\title{
Genetic characterization of G12P[6] and G12P[8] rotavirus strains collected in six African countries between 2010 and 2014
}

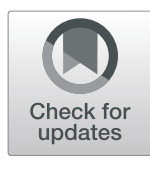

Kebareng G. Rakau1', Martin M. Nyaga ${ }^{1,2}$, Maemu P. Gededzha 1,3, Jason M. Mwenda ${ }^{4}$, M. Jeffrey Mphahlele ${ }^{1,5}$, L. Mapaseka Seheri ${ }^{1}$ and A. Duncan Steele ${ }^{1,6^{*}}$ (D)

\begin{abstract}
Background: G12 rotaviruses were first observed in sub-Saharan Africa in 2004 and since then have continued to emerge and spread across the continent and are reported as a significant human rotavirus genotype in several African countries, both prior to and after rotavirus vaccine introduction. This study investigated the genetic variability of 15 G12 rotavirus strains associated with either P[6] or P[8] identified between 2010 and 2014 from Ethiopia, Kenya, Rwanda, Tanzania, Togo and Zambia.

Methods: The investigation was carried out by comparing partial VP7 and partial VP4 sequences of the African G12P[6] and G12P[8] strains with the available GenBank sequences and exploring the recognized neutralization epitopes of these strains. Additionally, Bayesian evolutionary analysis was carried out using Markov Chain Monte Carlo (MCMC) implemented in BEAST to estimate the time to the most recent ancestor and evolutionary rate for these $\mathrm{G} 12$ rotavirus strains.

Results: The findings suggested that the VP7 and VP4 nucleotide and amino acid sequences of the G12 strains circulating in African countries are closely related, irrespective of country of origin and year of detection, with the exception of the Ethiopian strains that clustered distinctly. Neutralization epitope analysis revealed that rotavirus VP4 P[8] genes associated with G12 had amino acid sequences similar to those reported globally including the vaccine strains in RotaTeq and Rotarix. The estimated evolutionary rate of the G12 strains was $1.016 \times 10^{-3}$ substitutions/site/year and was comparable to what has been previously reported. Three sub-clusters formed within the current circulating lineage III shows the diversification of G12 from three independent ancestries within a similar time frame in the late 1990s.

Conclusions: At present it appears to be unlikely that widespread vaccine use has driven the molecular evolution and sustainability of G12 strains in Africa. Continuous monitoring of rotavirus genotypes is recommended to assess the long-term impact of rotavirus vaccination on the dynamic nature of rotavirus evolution on the continent.
\end{abstract}

Keywords: Rotavirus strains, Africa, G12, P[8], P[6]

\footnotetext{
* Correspondence: duncan.steele@gatesfoundation.org

'Diarrhoeal Pathogens Research Unit, Department of Virology, WHO AFRO

Rotavirus Regional Reference Laboratory, Sefako Makgatho Health Sciences University, Pretoria, South Africa

${ }^{6}$ Present address: Enteric and Diarrheal Diseases, Global Health, Bill \& Melinda Gates Foundation, Seattle, WA, USA

Full list of author information is available at the end of the article
}

(c) The Author(s). 2021 Open Access This article is licensed under a Creative Commons Attribution 4.0 International License, which permits use, sharing, adaptation, distribution and reproduction in any medium or format, as long as you give appropriate credit to the original author(s) and the source, provide a link to the Creative Commons licence, and indicate if changes were made. The images or other third party material in this article are included in the article's Creative Commons. licence, unless indicated otherwise in a credit line to the material. If material is not included in the article's Creative Commons licence and your intended use is not permitted by statutory regulation or exceeds the permitted use, you will need to obtain permission directly from the copyright holder. To view a copy of this licence, visit http://creativecommons.org/licenses/by/4.0/ The Creative Commons Public Domain Dedication waiver (http://creativecommons.org/publicdomain/zero/1.0/) applies to the data made available in this article, unless otherwise stated in a credit line to the data. 


\section{Background}

Diarrhoeal disease is a major cause of death in infants and young children below the age of 5 years and rotavirus is the most significant pathogen associated with that mortality [1]. Rotavirus is estimated to cause 122, 232-215,757 Under-5 deaths annually [2, 3]. Furthermore, it has been estimated that diarrhoeal diseases are significantly more severe in immunocompromised children, especially those infected with HIV which is relevant to sub-Saharan Africa [4]. Recent estimates showed that the introduction of rotavirus vaccines globally has resulted in a relative reduction of $59 \%$ of rotavirus hospitalizations and $36 \%$ of all cause acute gastroenteritis hospitalizations, respectively [5]. Before the introduction of rotavirus vaccines in many African countries, it was estimated that almost $40 \%$ of all diarrhoeal cases on the continent were due to rotavirus infection [4]. The introduction of rotavirus vaccines into 29 sub-Saharan African countries before 2016, resulted in a reduction of approximately 21,000 deaths and 135,000 hospitalizations in 2016 alone [6], highlighting the major impact that rotavirus vaccines have had on rotavirus diarrhoea.

Rotaviruses are double-stranded RNA (dsRNA) viruses, which belong to the family Reoviridae [7]. The viral genome comprises of eleven segments which code for six structural viral proteins (VP; labelled VP1-VP4, VP6-VP7) and six non-structural proteins (NSP; NSP1NSP6). Two of the structural proteins (VP7 and VP4) form the outer capsid of the virus, which are used in the binomial classification of rotavirus strains into $G$ (for the VP7 glycoprotein) and P (for the VP4 protease-sensitive) types, respectively. According to the Rotavirus Classification Working Group of the International Committee on Taxonomy of Viruses (ICTV), there are $36 \mathrm{G}$ and $51 \mathrm{P}$ rotavirus types causing diarrhoea in humans, animals and avian species [7-9]. Of these, only six genotypes G1P[8], G2P[4], G3P[8], G4P[8], G9P[8] and G12P[8] are responsible for over $90 \%$ of rotavirus-related diarrhoea in humans globally [10-12].

On the African continent the dominant VP7 genotypes of rotavirus are G1, G2, G3, G4, G8, G9 and G12; G4 strains predominated in the 1980s and 1990s but have subsequently diminished dramatically [13]. The common VP4 genotypes of human rotaviruses circulating are $\mathrm{P}[8], \mathrm{P}[6]$ and $\mathrm{P}[4]$ [14-16], with an unusually high prevalence of $\mathrm{P}[6]$ in Africa [16]. The emergence and rapid spread of $\mathrm{G} 12$ rotavirus strains has been widely observed globally [17]. A decade after the first report of G12 strains in the Philippines in 1987 [18], which was believed to be a zoonotic transmission to a child, the widespread circulation of this genotype was reported in South and North America, Asia and Europe [11, 18-21]. In sub-Saharan Africa, G12 strains initially emerged in combination with the VP4 P[6] genotype and were first reported in South Africa in 2004 during a hospital-based rotavirus surveillance study [22]. Subsequently, G12 rotavirus strains were reported in other African countries such as Malawi, Nigeria, Ghana, Cameroon, Kenya, Tanzania, Ethiopia, Zambia, Togo, and Zimbabwe [2329].

Interestingly, genotype G12 strains were prevalent in Africa during the evaluation of the available rotavirus vaccines (i.e. Rotarix and RotaTeq), in large safety and efficacy studies [30, 31]. Neither of these vaccines contain the G12 VP7 genotype although both have a VP4 $\mathrm{P}$ [8] genotype. RotaTeq (Merck \& Co., White River, Pennsylvania, USA) is a pentavalent bovine-human mono-reassortant vaccine containing 4 VP7 reassortants carrying the human G1 - G4 encoding genes and a VP4 reassortant carrying the human $\mathrm{P}[8]$ encoding gene, all on the genetic background of bovine rotavirus WI79 (G6 P[5]) strain [32]. Rotarix (GSK Biologicals, Rixensart, Belgium) is a human rotavirus strain bearing a G1P[8] genotype. The strain was isolated in 1989 [33].

Both rotavirus vaccines demonstrated homotypic and heterotypic protection against the common circulating strains in multiple studies in diverse geographies, including the circulating genotype G12 strain [34-38]. Furthermore, various post-marketing surveillance studies have reported that the vaccine confers heterotypic protection against novel strains carrying neither VP4 nor VP7 antigens found in the vaccines [39]. Nevertheless, there is concern in the scientific community about the issue of "vaccine-induced immune pressure" driving the emergence of novel strains that may evade vaccine protection [40]. As G12 rotavirus strains are the most recent to emerge and spread globally and are circulating in several African countries that have introduced the vaccine, and as information about the temporal genetic diversity of the circulating G12 strains in Africa is still limited, we sought to investigate the genetic variability of the two recognized neutralization antigens, VP7 and VP4, of G12 strains from across the continent. Thus, this study investigated the genetic variability of the gene segments 4 (encoding VP4) and 9 (encoding VP7) of G12 strains identified in several African countries and analysed the putative neutralization epitopes in an effort to provide insights on the evolutionary mechanisms and possible origins of the G12 strains in Africa.

\section{Methods}

\section{Ethical approval}

The University of Limpopo (MEDUNSA campus) (now called Sefako Makgatho Health Sciences University) Research \& Ethics Committee approved the study (MREC/ $\mathrm{P} / 237 / 2014)$.

The diarrheal stool samples were collected as a routine diagnostic clinical specimen when the parents brought 
their child to a health facility for clinical management, requiring no written informed consent. As part of the World Health Organization (WHO) coordinated rotavirus surveillance network, the archived rotavirus-positive specimens, were anonymized and utilized for strain characterization under a Technical Service agreement and a Materials Transfer Agreement (MTA) to the WHO Regional Office for Africa (WHO AFRO) Regional Reference Laboratory based at Sefako Makgatho Health Services University. The WHO Research Ethics Review Committee granted an 'exemption activity', noting that the procedures involved in the study are part of routine hospital-based rotavirus surveillance.

\section{Sample collection}

The stool samples were collected from children presenting with diarrhea during the 2010-2012 and 2014 rotavirus surveillance periods from six African countries (Ethiopia (ETH), Kenya (KEN), Rwanda (RWA), Tanzania (TZA), Togo (TGO), and Zambia (ZMB)). A standardised WHO generic protocol for hospital-based rotavirus surveillance was followed to recruit eligible children and collect the stool samples, as described elsewhere $[14,15]$. The samples were available at the Diarrhoeal Pathogens Research Unit (DPRU), a WHO Rotavirus Regional Reference Laboratory for rotavirus strain characterization based at Sefako Makgatho Health Sciences University. The samples were stored at $-20{ }^{\circ} \mathrm{C}$ until retrieved for this analysis. Fifteen rotavirus strains previously recorded as G12 by conventional genotyping methods [15] were selected for further analysis in this study. Table 1 lists the characteristics of the 15 selected G12 strains analysed in this study.

\section{Viral dsRNA extraction, VP4 and VP7 genotyping}

Viral dsRNA was extracted using QIAamp ${ }^{\bullet}$ viral RNA extraction kit (Qiagen, Hilden, Germany) as per manufacturer's instructions. The extracted dsRNA was subjected to reverse transcription polymerase chain reaction (RT-PCR) to amplify VP4 (partial VP8*) and VP7 genes using consensus primers sets Con2/Con3 and sBeg/End9, respectively [15, 22, 27]. Furthermore, to confirm the samples as G12 rotavirus strains, samples were genotyped using a cocktail of primers consisting of RVG9 and aBT1, aCT2, mG3, aDT4, aAT8v, mG9, mG10, newG12, representing G1, G2, G3, G4, G8, G9, G10 and G12 genotypes [37, 38]. The VP4 gene cocktail of primers which amplifies VP8* consisted of Con 3 and $1 \mathrm{~T}-1 \mathrm{D}, 2 \mathrm{~T}-1,3 \mathrm{~T}-1,4$ $\mathrm{T}-1$ and 4943 representing human rotavirus genotypes $\mathrm{P}[8], \mathrm{P}[4], \mathrm{P}[6], \mathrm{P}[11]$ and $\mathrm{P}[14][27,37]$. The sequences of primers used in this study are shown in Supplementary Table 1 . The PCR conditions were set out as described elsewhere [22, 37, 41, 42].

\section{Sanger sequencing}

Amplicons were sequenced using the dideoxynucleotide termination Sanger sequencing method with ABI 3500XL sequencer. A region of VP7 and VP4 was sequenced using reverse and forward primers used for RTPCR. The sequence chromatograms were edited using chromasPro version 1.49 beta resulting in 981 bp located at position 1-981 of the VP7 gene and approximately $731 \mathrm{bp}$ located from position $97-827$ of the VP4 gene fragments (www.technelysium.com.au/chromas.html).

Table 1 Demographics of the 15 G12P[8] and G12P[6] rotavirus genotypes

\begin{tabular}{|c|c|c|c|c|c|}
\hline Country of isolation & Common name & Year of identification & G-P types & VP4,VP7 accession number & Rotavirus vaccine introduction \\
\hline Ethiopia & MRC-DPRU2268 & 2011 & G12P[8] & MK059445, MK059430 & November 2013 Rotarix ${ }^{\circledast}$ \\
\hline Ethiopia & MRC-DPRU2273 & 2011 & G12P[8] & MK059448, MK059438 & \\
\hline Ethiopia & MRC-DPRU4959 & 2011 & G12P[8] & MK059446, MK059432 & \\
\hline Ethiopia & MRC-DPRU5683 & 2014 & G12P[8] & MK059442, MK059429 & \\
\hline Ethiopia & MRC-DPRU857 & 2012 & G12P[6] & MK059443, MK059431 & \\
\hline Kenya & MRC-DPRU1367 & 2012 & G12P[6] & MT995938, MK059435 & July 2014 Rotarix ${ }^{\circledast}$ \\
\hline Kenya & MRC-DPRU1369 & 2012 & G12P[6] & MK059435, MK059436 & \\
\hline Kenya & MRC-DPRU1377 & 2012 & G12P[6] & MK059449, MK059437 & \\
\hline Kenya & MRC-DPRU4288 & 2010 & G12P[6] & MK059447, MK059433 & \\
\hline Rwanda & MRC-DPRU6219 & 2014 & G12P[8] & MK059441, MK059439 & May 2012 RotaTeq $^{\oplus}$ \\
\hline Tanzania & MRC-DPRU4540 & 2011 & $\mathrm{G} 12 \mathrm{P}[8]$ & MK059451, MK059439 & January 2013 Rotarix ${ }^{\oplus}$ \\
\hline Togo & MRC-DPRU2118 & 2011 & G12P[8] & MK059452, MK059440 & June 2014 Rotarix ${ }^{\circledast}$ \\
\hline Zambia & MRC-DPRU1765 & 2012 & G12P[6] & MK059444, MK059426 & January 2012 Rotarix ${ }^{\oplus}$ \\
\hline Zambia & MRC-DPRU2495 & 2011 & G12P[6] & MT995937, MK059427 & \\
\hline Zambia & MRC-DPRU4165 & 2010 & G12P[8] & MK059450, MK059434 & \\
\hline
\end{tabular}




\section{Sequence analysis}

Sequencing data was then compared with available rotavirus sequences in the GenBank database using the NCBI-BLAST software (www.ncbi.nlm.nih.gov/BLAST/, USA). The VP7 and VP4 alignments were made using the MUSCLE algorithm implemented in MEGA 6 software $[43,44]$. To expand the analysis, VP7 G12 and VP4 $\mathrm{P}[8]$ sequences from other African countries available in the GenBank were downloaded and included in the alignments. Once aligned, the DNA Model Test program implemented in MEGA version 6 was used to identify optimal evolutionary models that best fit sequence datasets. Using the Corrected Akaike Information Criterion (AICc) the following models; GTR + G (VP7), T92 + G (VP4 P[8]) and GTR + G + I (VP4 P[6]) were utilized. Using these models, maximum-likelihood trees were constructed using MEGA 6 with 1000 bootstrap replicates to estimate branch support. Nucleotide and amino acid sequence identities among strains were calculated for each gene based on distance matrices prepared using the p-distance algorithm in MEGA 6 software [43]. Dot conservation plots were constructed using BioEdit sequence alignment editor [45] identifying the variable and antigenic regions within the VP7 gene [46, 47] of the study strains with G12 reference strains belonging to the four G12 lineages (I-IV).

Simultaneously, P[8] VP4 sequences of the study strains were compared with $\mathrm{P}[8]$ of both the Rotarix and RotaTeq vaccine strains and other recent circulating strains; while the P[6] VP4 sequences were analysed by comparison with other globally circulating $\mathrm{P}[6]$ reference strains.

To estimate the rate of evolution (substitutions per site per year) and the time of the most recent common ancestor of the G12 genotype, 114 G12 VP7 sequences isolated between 1987 and 2019, representing the temporal span of these genotypes from the first G12 isolate to contemporary strains, and spanning global distribution of these strains, were retrieved from GenBank together with our study strains. To investigate the temporal signal of the sequences and to remove sequences that might be diverse, the G12 maximum likelihood phylogenetic tree was analysed in TempEST v1.5.3 [48], a tool that assesses the association of root-to-tip divergence and sampling of each sequence. Finally, Bayesian Markov chain Monte Carlo (MCMC) analysis was performed in BEAST v.1.6 software package, (http://beast.bio.ed.ac.uk). Several models with different priors were initially tested and compared using Bayes factor. Then the following Bayesian parameters were set out $\mathrm{GTR}+\mathrm{G}$ substitution model, uncorrelated exponential relaxed clock lognormal model [49] and coalescent Bayesian skyline tree prior [50]. This analysis was run four times at 50 million generations. The individual runs were combined with LogCombiner and Tracer v.1 (http://tree.bio.ed.ac.uk/ software/tracer/) was used to view the results and effective sampling size (ESS) values of $>200$ indicated sufficient sampling. Maximum clade credibility trees were annotated using TreeAnnotator v.1.6.2 and visualized in FigTree v.1.4.3 (http://tree.bio.ed.ac.uk/software/figtree/).

\section{Accession numbers}

The partial VP7 and VP4 sequences have been made available on the NCBI GenBank database (Accession numbers: MK059426 - MK059453; MT995937-MT995938).

\section{Results}

\section{VP7 genotype analysis}

The nucleotide and amino acid sequences of 15 G12 rotavirus strains collected during 2010-2014 rotavirus seasons across Africa, were analysed and compared with the strains from the GenBank database. High nucleotide (96.8-99.9\%) and amino acid (98.1-100\%) sequence similarity was observed amongst the VP7 gene sequence of the G12 study strains as well as between the study strains and circulating global human G12 strains. One strain, MRC-DPRU6219 from Rwanda, shared 95.898.0\% nucleotide and 97.2-98.7\% amino acids identity with the other 14 study strains (Supplementary Table 2).

Phylogenetic analysis showed that the African rotavirus genotype G12 VP7 sequences clustered within lineage III, and sub-lineage III A-C (labelled for the purpose of discussion in this study) (Fig. 1). The two study strains, MRC-DPRU4540 (Tanzania) and MRCDPRU2118 (Togo) in sub-lineage IIIA were closely related to globally circulating non-African G12 strains, and to Nigerians strains collected in 2012 and 2013, respectively. The G12 strains included in this study from Ethiopia (MRC-DPRU2268, MRC-DPRU857, MRCDPRU2273， MRC-DPRU5683， MRC-DPRU4959 and MRC-DPRU4165) formed a monophyletic cluster within sub-lineage IIIB with reference strains from Nepal and Belgium. The study strains isolated from Kenya and Zambia clustered in sub-lineage IIIC and closely related to other African G12 strains. Interestingly most of these African strains all shared a G12P[6] genotypic constellation. Within the same IIIC sub-lineage a single Rwandan strain (MRC-DPRU6219) isolated in 2014 seemed distinct and clustered closer to strains isolated from Mozambique and India.

The temporal signal analysis of G12 maximum likelihood phylogenetic tree analysed in TempEST reported a correlation coefficient of 0.6213 and R-squared value of 0.386 which suggests a strong association and high effect size of the G12 sequences. The linear regression plot shows clustering of G12 sequences around 2010 (Supplementary Figure 1). Evolutionary analysis in BEAST generated ESS values that were $>200$ for all parameters. The estimated evolutionary rate for G12 was $1.16 \times 10^{-3}$ nucleotide substitutions/site/year with $95 \%$ high 


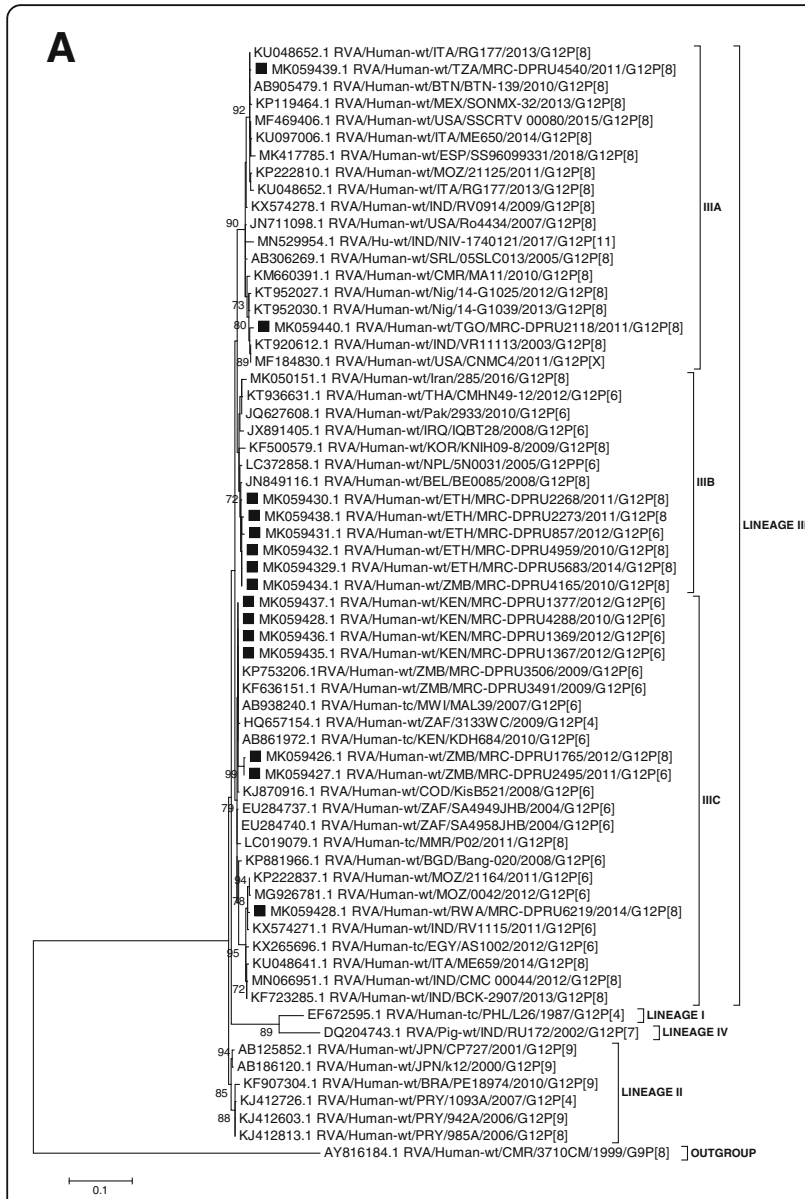

B

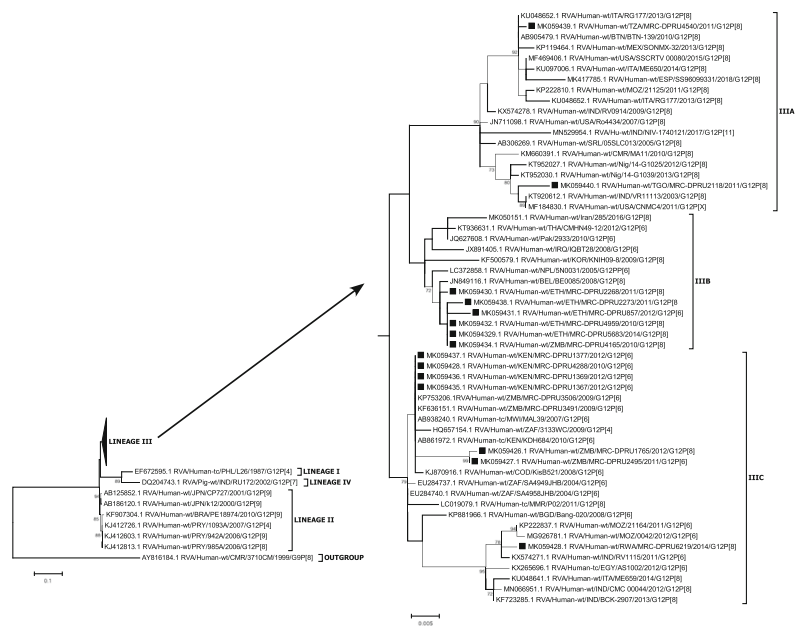

Fig. 1 a Complete Maximum likelihood G12 tree illustrating the branching of the four G12 lineages and sub-lineages. b G12P[8] and G12P[6] VP7 maximum likelihood tree constructed from African G12 rotavirus nucleotide sequences from six countries and selected published human and porcine rotavirus reference strains. Bootstraps $>70$ are shown on the branch length. Key: The African G12 strains are indicated in black and the countries abbreviated as follows: Ethiopia-ETH, Kenya-KEN, Rwanda-RWA, Tanzania-TZA, Togo-TGO and Zambia-ZMB

posterior density interval (95\%HPD) of $7.23 \times 10^{-4}$ to $1.30 \times 10^{-3}$. The most recent common ancestor for lineage III, which consists of the current circulating strains, was dated back to 1992 (Fig. 2). Maximum clade credibility tree also displayed the diversification of lineage III strains into sub-clusters similar to the maximum likelihood phylogenetic tree. The three subclusters most common recent ancestors were estimated to 1997 for IIIA, 1999 for IIIB and 1997 for IIIC.

Sequence analysis within the nine variable regions (VR) and four antigenic regions (AR, A-C,F) of VP7 of the study strains were considerably conserved when compared to the first reported African G12 strain from South Africa (SA4958JHB) as well as representative strains belonging to the four lineages. The comparison of the amino acid showed differences mostly within the variable regions of the gene compared to the antigenic regions which carry the recognized antigen-specific epitopes (Table 2). Although the study strains were related to the first reported South African strain, at certain positions the study strains shared amino acids similar to the prototype (L26, lineage I) and porcine (RU172, lineage IV) G12 strains. For instance, amino acid substitution M44I observed in multiple study strains was similar to the L26 and RU172 strains.

Interestingly, in antigenic region A, strains from Ethiopia and Zambia had an N100S amino acid substitution. An alignment of G12 lineage III strains circulating globally identifies this substitution as found in strains from Nepal, Italy and Belgium but not from other African strains (data not shown). Certain amino acids were unique to strains belonging to specific lineages such as amino acid substitutions - N100H, D130N in the prototype strain (L26, lineage I), the I40A, T65A, A122T in the porcine strain (RU172, lineage IV) and A68T in the 985A strain (lineage II). Furthermore, notable amino acid substitutions A125S and V142I differentiated lineage III isolates from those in lineages I, II and IV. This substitution was seen in all global G12 strains belonging to lineage III. 


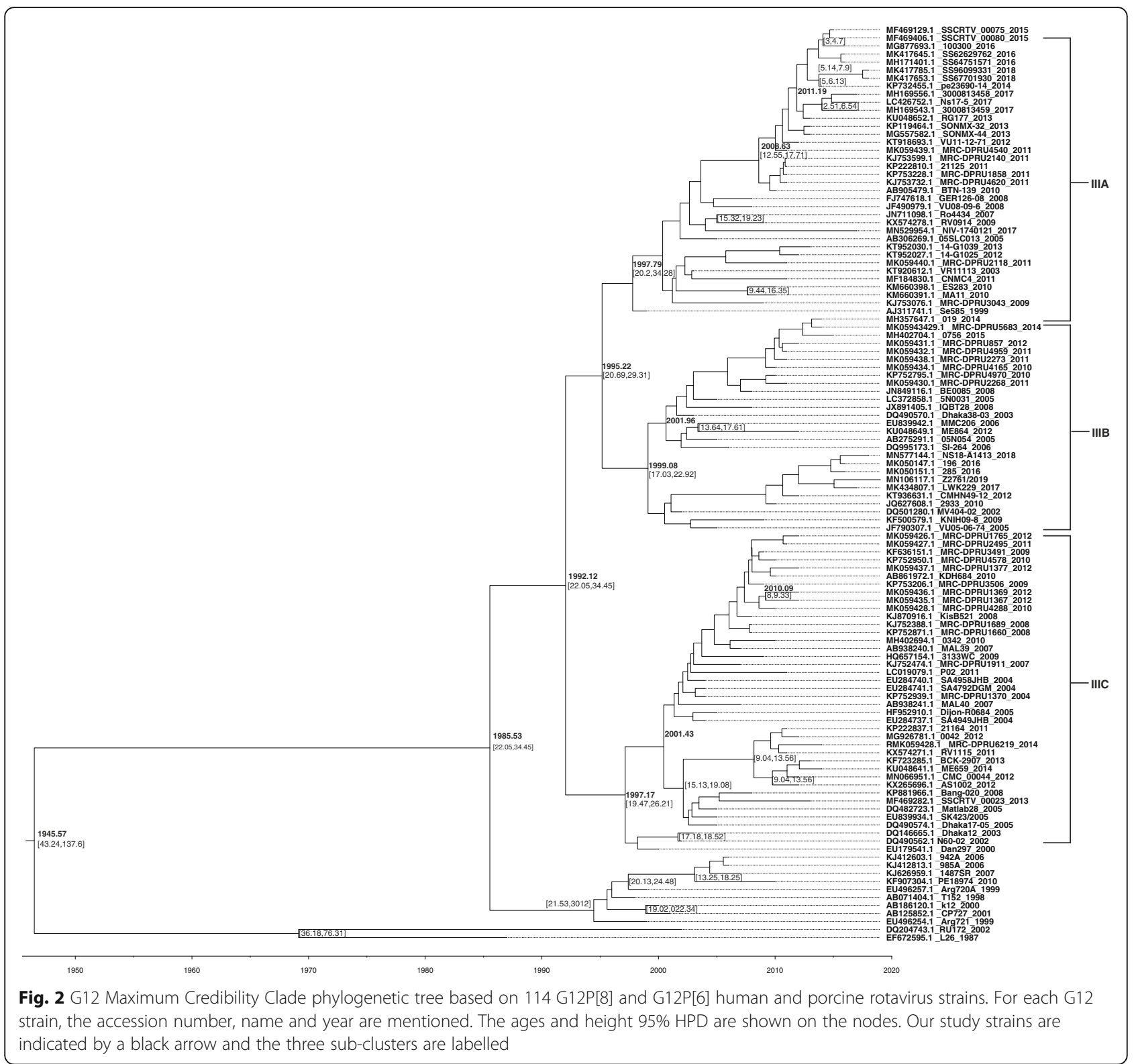

\section{VP4 genotype analysis}

The partial VP8* gene sequence of VP4 (876 bp) was also analysed for the 15 study strains and compared to sequences in GenBank. Of the sequences analysed, both $\mathrm{P}[8](n=8)$ and $\mathrm{P}[6](n=7)$ strains were included. Sequence comparison showed that the G12P[8] strains shared 98.4-99.9\% nucleotide and 98.1-100\% amino acid similarity with most African P[8] strains available in the GenBank database. Also, they shared similar percentage similarity with each other (Supplementary Table 3). The $\mathrm{P}[8]$ rotavirus strains clustered in lineage III distantly from the Rotarix and RotaTeq P[8] vaccine components, which clustered in lineage I and lineage II, respectively (Fig. 3). Four of the five strains from Ethiopia formed their own monophyletic cluster as was also seen with their VP7 sequences. While MRCDPRU5683 (Ethiopia), MRC-DPRU2118 (Togo), MRCDPRU6219 (Rwanda) and MRC-DPRU4540 (Tanzania) scattered throughout the phylogenetic tree, clustering closer to strains from Hungary, USA, Australia and India, respectively.

The comparison of the eight strains bearing VP4 P[8] genotype with the VP4 P[8] gene included in the two vaccines, Rotarix and RotaTeq, and other strains representing different $\mathrm{P}[8]$ lineages, revealed that the strains are highly conserved with a few amino acid substitutions within the VP8* neutralizing antigenic epitopes. Within VP8* there are four defined neutralization epitopes, designated 8-1 to 8-4 [51] (Table 3). As shown in Table 3, the study strains had similar amino acid substitutions 
Table 2 A-E: Comparison of the nine variable regions (VR) and four antigenic regions (AR) in VP7 (defined in references [46, 47]) of the 15 study strains with reference strains representing all four G12 lineages. Amino acid substitutions within the study strains are bolded, grey areas indicate antigenic regions and * indicates that the amino acid is conserved

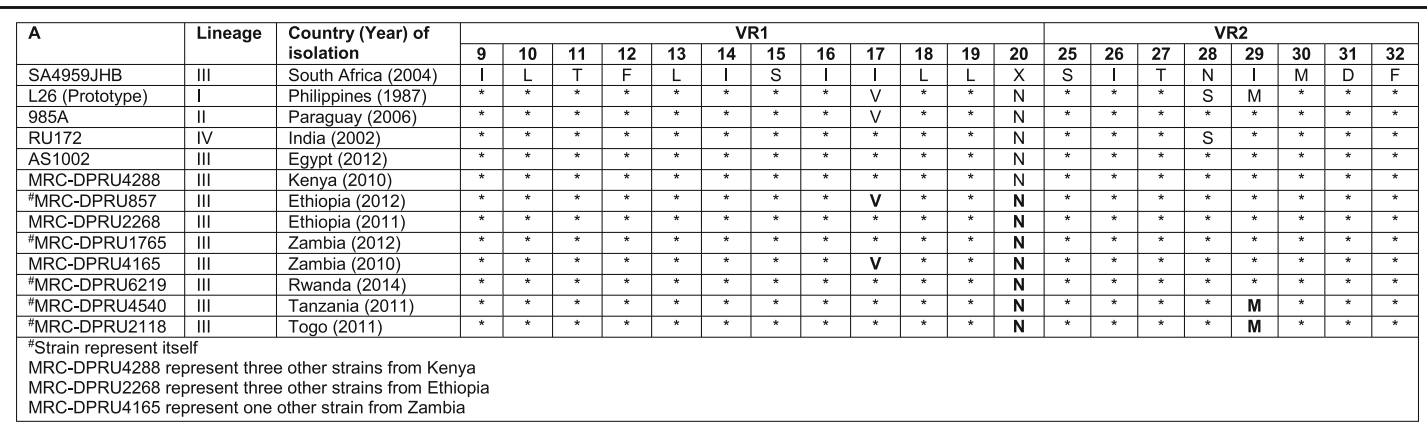
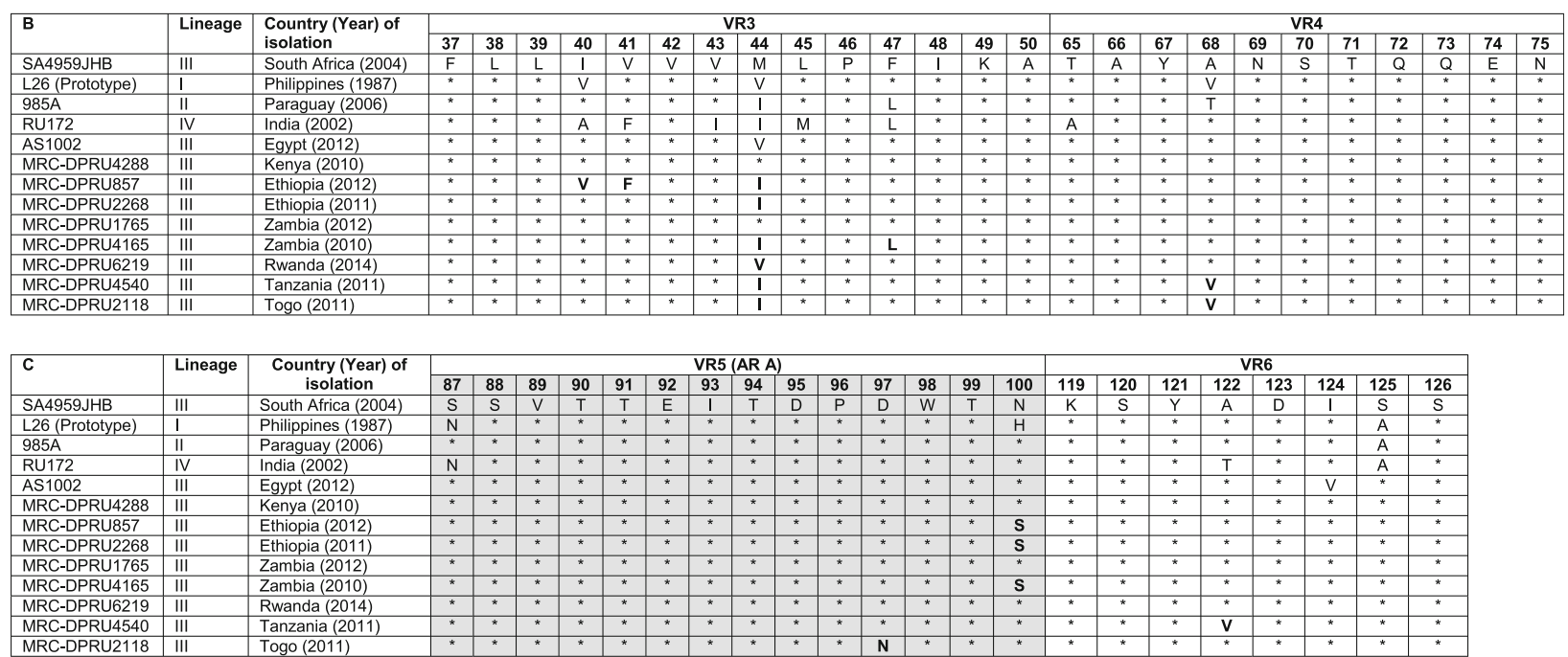

\begin{tabular}{|c|c|c|c|c|c|c|c|c|c|c|c|c|c|c|c|c|c|c|c|c|c|c|c|}
\hline \multirow[t]{2}{*}{ D } & \multirow{2}{*}{ Lineage } & \multirow{2}{*}{$\begin{array}{l}\text { Country (Year) of } \\
\text { isolation }\end{array}$} & \multicolumn{10}{|c|}{ VR6 } & & \multicolumn{10}{|c|}{ VR7 (AR B) } \\
\hline & & & 127 & 128 & 129 & 130 & 131 & 132 & 133 & \begin{tabular}{|l|l|}
134 \\
$y$
\end{tabular} & 135 & \begin{tabular}{|l|l|}
136 \\
\end{tabular} & 137 & 141 & 142 & \begin{tabular}{|l|}
143 \\
\end{tabular} & \begin{tabular}{|l|l|}
144 \\
\end{tabular} & 145 & 146 & $\frac{147}{s}$ & 148 & 149 & 150 \\
\hline SA4959JHB & IIII & $\begin{array}{l}\text { South Africa } \\
(2004)\end{array}$ & $F$ & $\mathrm{~s}$ & V & $D$ & $P$ & $Q$ & $\mathrm{~L}$ & Y & c & $\mathrm{D}$ & Y & $\mathrm{L}$ & & Q & Y & $Q$ & $\mathrm{~N}$ & s & L & A & $\begin{array}{ll} \\
\end{array}$ \\
\hline ee) & 1 & Philippines (1987) & * & & & $\mathrm{N}$ & ${ }^{*}$ & * & * & * & & & & & v & * & * & & * & & & & \\
\hline & 1 & aguay (2006) & * & * & * & * & $*$ & * & * & * & $*$ & * & * & $*$ & $\mathrm{v}$ & * & $*$ & * & * & * & * & * & * \\
\hline & I) & & ${ }^{*}$ & ${ }^{*}$ & * & * & * & * & * & * & * & * & * & $*$ & $\mathrm{v}$ & * & * & * & * & * & & * & \\
\hline & III & E & $*$ & ${ }^{*}$ & * & ${ }^{*}$ & ${ }^{*}$ & * & $*$ & * & * & * & * & $*$ & $*$ & * & * & * & * & * & * & * & ${ }^{*}$ \\
\hline MRC & & K & ${ }^{*}$ & $*$ & * & $*$ & $*$ & * & & & * & * & * & $*$ & $*$ & $\star$ & & & & & & & * \\
\hline & III & Et & $*$ & * & * & * & $*$ & $\star$ & * & * & $*$ & * & * & $*$ & * & 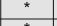 & $*$ & $*$ & $*$ & $*$ & $*$ & * & ${ }^{*}$ \\
\hline MRC-DF & III & Ethio & 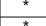 & $\star$ & $*$ & $*$ & $\star$ & * & $*$ & * & $*$ & $*$ & 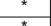 & *: & $*$ & * & * & * & $*$ & ${ }^{*}$ & $*$ & $\star *$ & ${ }^{*}$ \\
\hline & IIII & & $*$ & $*$ & $*$ & $*$ & $*$ & * & * & * & ${ }^{*}$ & ${ }^{*}$ & $*$ & $*$ & * & 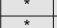 & * & * & * & ${ }^{*}$ & * & ${ }^{*}$ & $*$ \\
\hline \begin{tabular}{|l} 
MRCLL \\
MRC-D
\end{tabular} & IIII & $\begin{array}{l}\text { Lambia }(2010) \\
\text { Rwanda (2014) }\end{array}$ & $*$ & $*$ & * & * & $\approx$ & * & * & * & * & * & * & * & * & * & * & * & * & * & * & * & $*$ \\
\hline $\mathrm{MR}_{2}$ & III & Tanzania (2011) & * & * & * & * & $*$ & * & * & * & ${ }^{*}$ & * & * & ** & * & $*$ & * & ${ }^{*}$ & $*$ & $*$ & * & * & * \\
\hline$C-[$ & & Togo (2011 & & * & * & * & * & * & * & * * & * & * & * & * & * & * & $*$ & * & * & * & * & * & \\
\hline
\end{tabular}

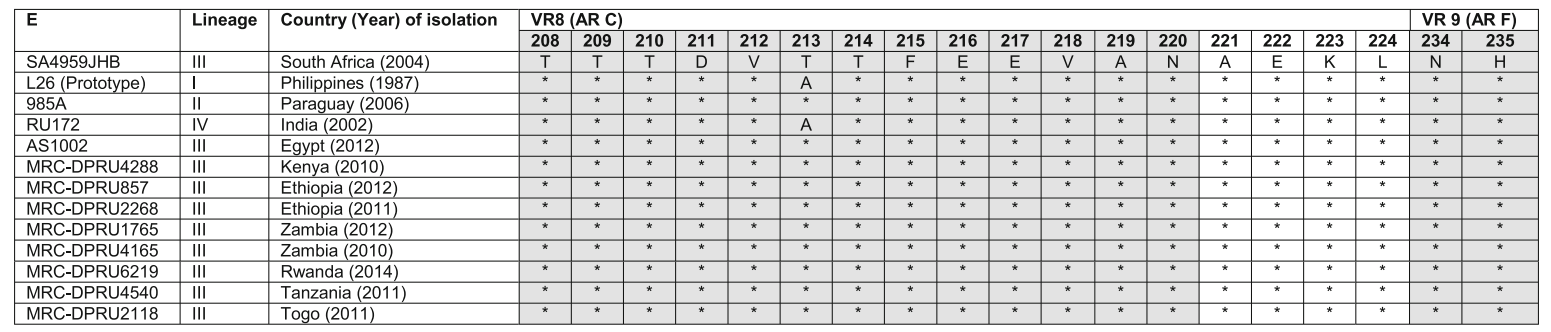

(S125N and S131R) with the VP4 of RotaTeq. This S131R substitution is common with other strains in lineages II to IV, but not with Rotarix which lies in lineage I. At positions 150 and 113 , both the vaccine VP4 components were the same as the study strains (except for the monophyletic strains from Ethiopia which carried E150D and N113D substitutions). The S146G amino acid change was observed in all the study strains and the 


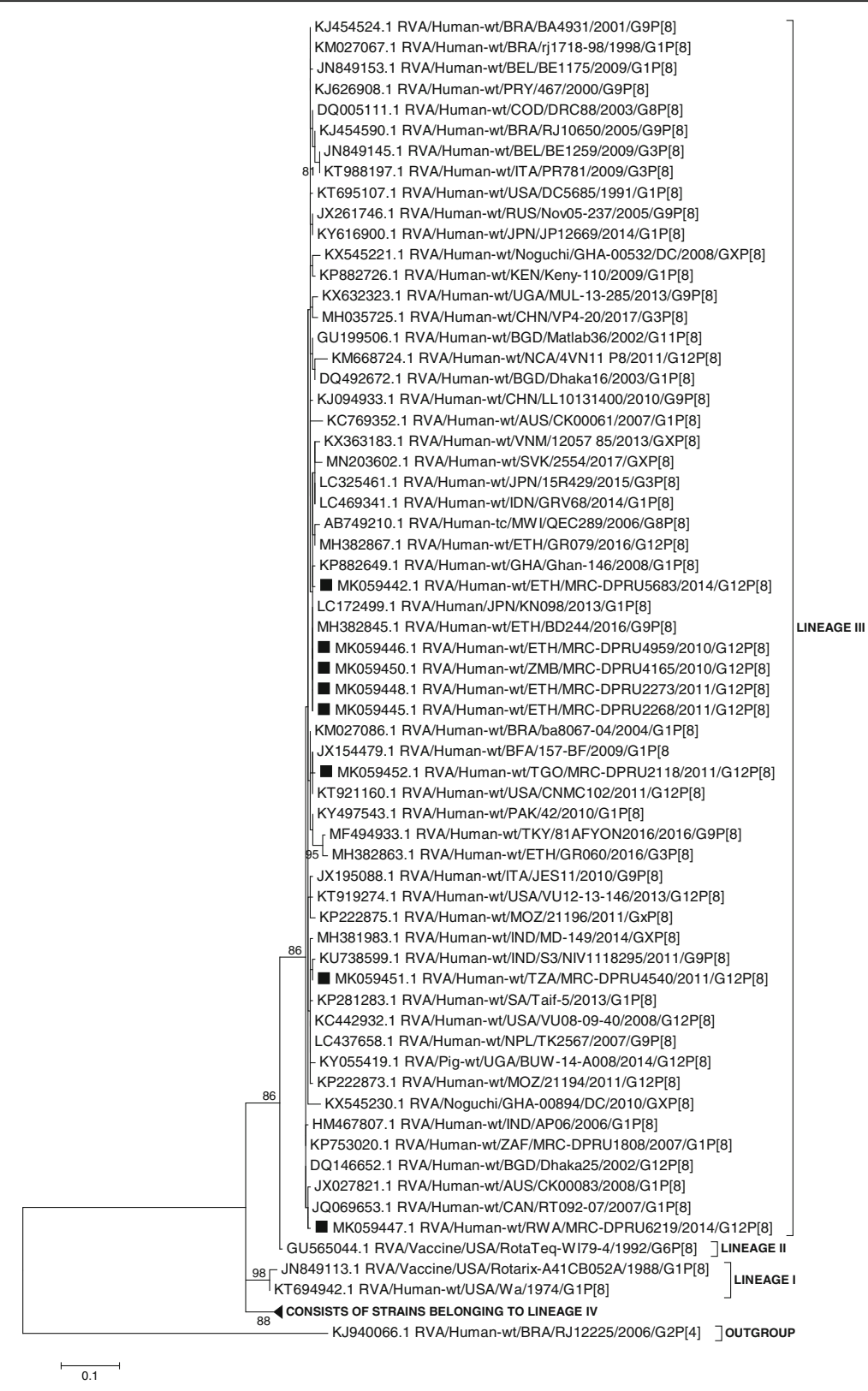

Fig. 3 G12P[8] VP4 maximum likelihood tree constructed from African rotavirus nucleotide sequences from six countries and selected human rotavirus reference strains. Partial and complete sequences for reference strains were included in the analysis. Bootstraps $>70$ are shown on the branch length. Key: The study sequences are indicated in black and the countries are abbreviated as follows: Ethiopia-ETH, Kenya-KEN, RwandaRWA, Tanzania-TZA, Togo-TGO and Zambia-ZMB

lineage III-IV reference strains, and distinct from Rotarix and RotaTeq. Finally, the study strains as well as the lineage III reference strain, had N195G amino acid change differentiating lineage III from lineages I (Rotarix), II (RotaTeq) and IV (MRC-DPRU2144).

Similarly, the P[6] study strains shared 95.9-99.7\% nucleotide and $97.1-100 \%$ amino acid similarity amongst themselves and with $\mathrm{P}[6]$ sequences available in the GenBank database. However, strain MRC-DPRU857 from Ethiopia shared fewer nucleotide and amino acid similarity with the study strains, $95.9-97.1 \%$ and $97.5-$ 98.8\% respectively (Supplementary Table 4). The P[6] study strains clustered in lineage Ia with other global strains and tended to cluster more closely with other African strains (Fig. 4). Amino acid conservation plot of the study strains with other $\mathrm{P}[6]$ strains representing the four lineages show that the study strains are conserved within lineage I into which the study strains clustered 
Table 3 A-B Comparison of G12P[8] rotavirus strains with P[8] vaccine components of Rotarix and RotaTeq and other recent strains representing the P[8] lineages within the VP8* antigenic epitopes (defined in references [47, 50]). Amino acids substitutions within the studied strains are bolded and ${ }^{*}$ indicates the amino acid is conserved

\begin{tabular}{|c|c|c|c|c|c|c|c|c|c|c|c|c|c|c|c|c|c|c|c|c|}
\hline \multirow[t]{2}{*}{$A$} & \multirow{2}{*}{$\begin{array}{l}\mathrm{P}[8] \\
\text { Lineage }\end{array}$} & \multirow{2}{*}{$\begin{array}{l}\text { Country (Year) of } \\
\text { isolation }\end{array}$} & \multicolumn{10}{|l|}{$8-1$} & \multicolumn{2}{|l|}{$8-2$} & \multicolumn{6}{|l|}{$8-3$} \\
\hline & & & 100 & 146 & 148 & 150 & 188 & 190 & 192 & 193 & 194 & 195 & 180 & 183 & 113 & 114 & 115 & 116 & 125 & 131 \\
\hline $\begin{array}{l}\text { Rotarix }^{\oplus} \\
\text { (Vaccine) }\end{array}$ & । & USA (1989) & $\mathrm{D}$ & S & Q & $E$ & S & T & N & L & $\mathrm{N}$ & N & T & $A$ & N & $P$ & V & $\mathrm{D}$ & S & S \\
\hline $\begin{array}{l}\text { RotaTeq } \\
\text { (Vaccine) }\end{array}$ & $\|$ & USA (1992) & * & * & * & * & * & * & * & * & * & $\mathrm{D}$ & * & * & * & * & * & * & $\mathrm{N}$ & $\mathrm{R}$ \\
\hline GR079 & III & Ethiopia (2016) & $*$ & G & * & $\mathrm{D}$ & $*$ & * & * & * & * & G & * & * & $\mathrm{D}$ & * & $*$ & * & $\mathrm{N}$ & $\mathrm{R}$ \\
\hline $\begin{array}{l}\text { MRC- } \\
\text { DPRU2144 }\end{array}$ & IV & South Africa (2004) & * & G & * & * & * & * & D & * & * & S & * & * & * & * & * & * & * & $\mathrm{R}$ \\
\hline $\begin{array}{l}\text { MRC- } \\
\text { DPRU2268 }\end{array}$ & III & Ethiopia (2011) & $*$ & $\mathbf{G}$ & * & D & $*$ & * & * & * & * & G & * & * & D & * & * & * & $\mathbf{N}$ & $\mathbf{R}$ \\
\hline $\begin{array}{l}\text { \#MRC- } \\
\text { DPRU6219 }\end{array}$ & III & Rwanda (2014) & * & G & * & * & * & * & * & * & * & G & * & * & * & * & * & * & $\mathbf{N}$ & $\mathbf{R}$ \\
\hline $\begin{array}{l}\text { \#MRC-DPRU } \\
2118\end{array}$ & III & Togo (2011) & * & G & * & * & * & * & * & * & * & G & * & * & * & * & * & * & $\mathrm{N}$ & $\mathbf{R}$ \\
\hline \multirow[t]{2}{*}{ B } & \multirow{2}{*}{$\begin{array}{l}\mathrm{P}[8] \\
\text { Lineage }\end{array}$} & \multirow{2}{*}{$\begin{array}{l}\text { Country (Year) of } \\
\text { isolation }\end{array}$} & \multicolumn{3}{|l|}{$8-3$} & \multicolumn{3}{|l|}{$8-4$} & & & & & & & & & & & & \\
\hline & & & 132 & 133 & 135 & 87 & 88 & 89 & & & & & & & & & & & & \\
\hline $\begin{array}{l}\text { Rotarix } \\
\text { (Vaccine) }\end{array}$ & I & USA (1989) & $\mathrm{N}$ & D & V & $\mathrm{N}$ & T & $\mathrm{N}$ & & & & & & & & & & & & \\
\hline $\begin{array}{l}\text { RotaTeq } \\
\text { (Vaccine) }\end{array}$ & $\|$ & USA (1992) & * & * & * & * & * & * & & & & & & & & & & & & \\
\hline GR079 & III & Ethiopia (2016) & * & * & * & * & * & * & & & & & & & & & & & & \\
\hline $\begin{array}{l}\text { MRC- } \\
\text { DPRU2144 }\end{array}$ & IV & South Africa (2004) & * & * & * & * & * & * & & & & & & & & & & & & \\
\hline $\begin{array}{l}\text { MRC- } \\
\text { DPRU2268 }\end{array}$ & III & Ethiopia (2011) & * & * & * & * & * & * & & & & & & & & & & & & \\
\hline $\begin{array}{l}\text { MRC- } \\
\text { DPRU6219 }\end{array}$ & III & Rwanda (2014) & * & * & * & * & * & * & & & & & & & & & & & & \\
\hline $\begin{array}{l}\text { MRC-DPRU } \\
2118\end{array}$ & III & Togo (2011) & * & * & * & * & * & * & & & & & & & & & & & & \\
\hline
\end{tabular}

\#Strain represent itself

MRCDPRU2268 represent three other strains from Ethiopia, one from Tanzania and one from Zambia

(Table 4). S146N was the only substitution detected in MRC-DPRU1369 strain isolated from Kenya, which was like reference strains representing lineage II-IV.

\section{Discussion}

This study analysed circulating G12P[6] and G12P[8] rotaviruses from several African countries collected during the period 2010-2014 and prior to widespread use of rotavirus vaccines on the continent. Genotype G12 strains, which emerged approximately two decades ago, have been reported to be the cause of severe dehydrating diarrhoea in vaccinated children in several countries, particularly in Latin America which started vaccination about six years prior to sub-Saharan Africa [52-54]. However, if one looks at a temporal association of the emergence of the G12 strains, it is associated with the global spread of these strains, rather than causally associated with wide-spread vaccine use. Nevertheless, with the introduction of rotavirus vaccine in 2012-2014 in many of the African countries included in this study, the opportunity existed to conduct an analysis of circulating G12P[6] and G12P[8] strains in several countries, just prior to and as vaccines were introduced and to evaluate whether these strains might become predominant due to evading the vaccine. Five of the six studied countries had introduced the Rotarix vaccine with the exception of Rwanda which initially introduced RotaTeq vaccine and switched to Rotarix in 2018.

Clearly, G12 strains do not share the VP7 G-specificity with vaccine strains; however, both licenced rotavirus vaccines (RotaTeq and Rotarix) have demonstrated clinical protection against heterotypic strains, including G12 strains. For instance, the phase III Rotarix clinical trial conducted in Malawi and South Africa showed cross 


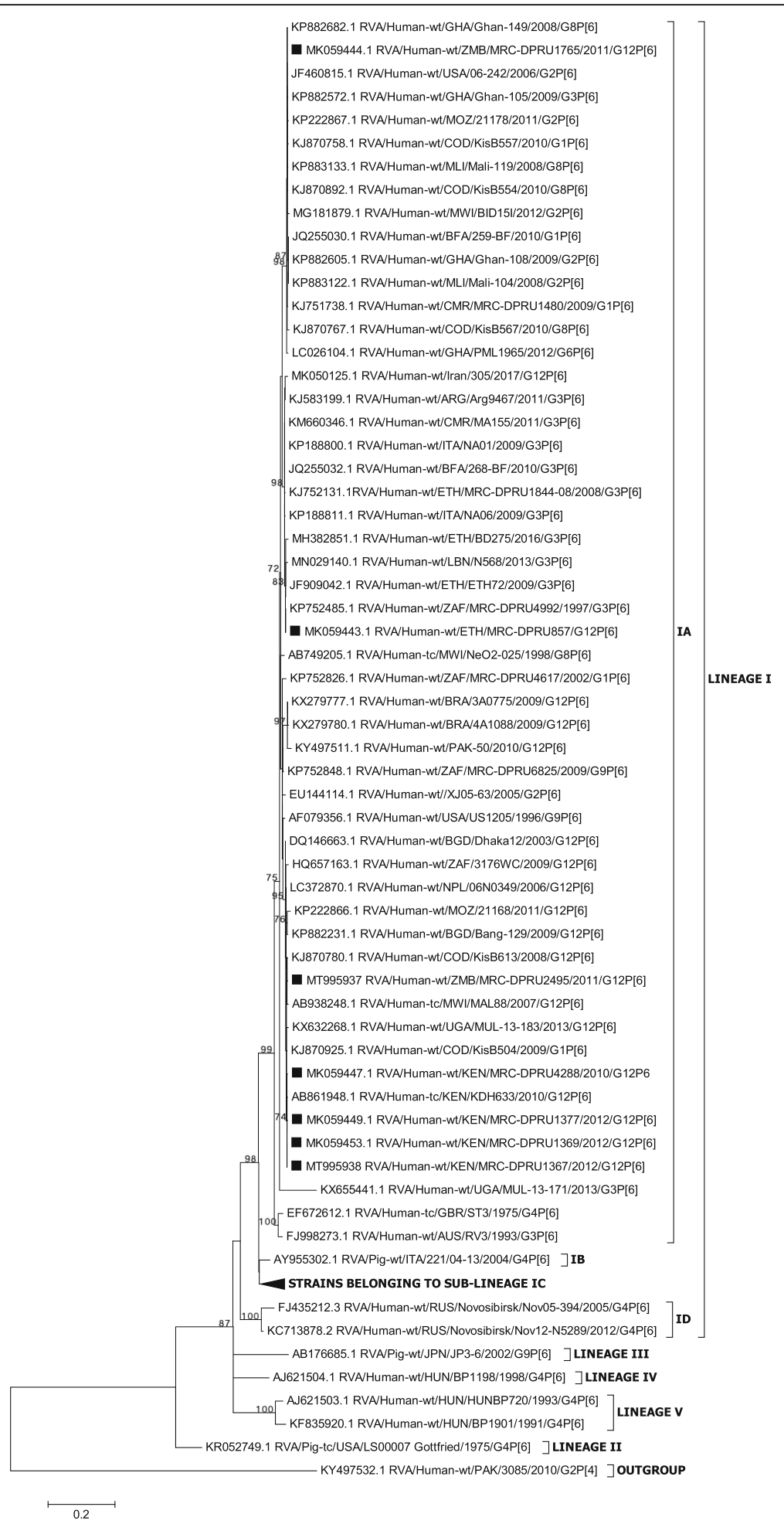

Fig. 4 G12P[6] VP4 maximum likelihood tree constructed from African rotavirus nucleotide sequences from six countries and selected human rotavirus reference strains. Partial and complete sequences for reference strains were included in the analysis. Bootstraps $>70$ are shown on the branch length. Key: The study sequences are indicated in black and the countries are abbreviated as follows: Ethiopia-ETH, Kenya-KEN, RwandaRWA, Tanzania-TZA, Togo-TGO and Zambia-ZMB 
Table 4 A-B Comparison of G12P[6] strains with reference P[6] strains representing the four P[6] lineages within the VP8* antigenic regions $[47,50]$. Amino acids substitutions within the studied strains are bolded and ${ }^{*}$ indicates the amino acid is conserved

\begin{tabular}{|c|c|c|c|c|c|c|c|c|c|c|c|c|c|c|c|c|c|c|c|c|}
\hline \multirow[t]{2}{*}{ A } & \multirow{2}{*}{$\begin{array}{l}\mathrm{P}[6] \\
\text { Lineage }\end{array}$} & \multirow{2}{*}{$\begin{array}{l}\text { Country (Year) of } \\
\text { isolation }\end{array}$} & \multicolumn{10}{|l|}{$8-1$} & \multicolumn{2}{|l|}{$8-2$} & \multicolumn{6}{|l|}{$8-3$} \\
\hline & & & 100 & 146 & 148 & 150 & 188 & 190 & 192 & 193 & 194 & 195 & 180 & 183 & 113 & 114 & 115 & 116 & 125 & 131 \\
\hline 305 & I & Iran (2017) & D & S & S & E & S & $\mathrm{T}$ & N & L & S & $\mathrm{E}$ & T & A & T & $\mathrm{N}$ & Q & S & T & $E$ \\
\hline Gottrified & $\|$ & USA (1975) & * & $\mathrm{N}$ & $\mathrm{N}$ & $D$ & * & * & * & * & $P$ & $D$ & * & * & $P$ & S & * & $\mathrm{D}$ & V & * \\
\hline JP3-6 & III & Japan & * & $\mathrm{N}$ & * & * & * & * & * & * & Y & $\mathrm{D}$ & * & * & V & S & * & $*$ & * & * \\
\hline B1198 & IV & Hungary (1998) & * & $\mathrm{N}$ & * & * & * & * & * & $*$ & * & * & * & * & * & * & * & * & * & * \\
\hline $\begin{array}{l}\text { MRC- } \\
\text { DPRU1765 }\end{array}$ & I & Zambia (2012) & * & * & * & * & * & * & * & * & * & * & * & * & * & $*$ & $*$ & * & * & $*$ \\
\hline $\begin{array}{l}\text { MRC- } \\
\text { DPRU1369 }\end{array}$ & । & Kenya (2012) & * & $\mathbf{N}$ & * & * & * & * & $*$ & * & * & * & * & * & * & * & * & $*$ & * & * \\
\hline $\begin{array}{l}\text { "MRC- } \\
\text { DPR857 }\end{array}$ & । & Ethiopia (2012) & * & * & * & * & * & $*$ & * & * & * & * & * & * & * & * & * & $*$ & * & * \\
\hline \multirow[t]{2}{*}{ B } & \multirow{2}{*}{$\begin{array}{l}\mathrm{P}[6] \\
\text { Lineage }\end{array}$} & \multirow{2}{*}{$\begin{array}{l}\text { Country (Year) of } \\
\text { isolation }\end{array}$} & \multicolumn{3}{|l|}{$8-3$} & \multicolumn{3}{|l|}{$8-4$} & & & & & & & & & & & & \\
\hline & & & 132 & 133 & 135 & 87 & 88 & 89 & & & & & & & & & & & & \\
\hline 305 & I & Iran (2017) & $N$ & $N$ & $\mathrm{~N}$ & T & $\mathrm{N}$ & Q & & & & & & & & & & & & \\
\hline Gottrified & $\|$ & USA (1975) & * & S & D & I & * & K & & & & & & & & & & & & \\
\hline JP3-6 & III & Japan & * & * & * & * & * & * & & & & & & & & & & & & \\
\hline B1198 & IV & Hungary (1998) & * & S & $*$ & * & $*$ & * & & & & & & & & & & & & \\
\hline $\begin{array}{l}\text { MRC- } \\
\text { DPRU1765 }\end{array}$ & I & Zambia (2012) & * & * & * & * & * & * & & & & & & & & & & & & \\
\hline $\begin{array}{l}\text { MRC- } \\
\text { DPRU1369 }\end{array}$ & I & Kenya (2012) & * & * & * & * & * & * & & & & & & & & & & & & \\
\hline $\begin{array}{l}\text { MRC- } \\
\text { DPR857 }\end{array}$ & I & Ethiopia (2012) & * & * & * & $*$ & * & * & & & & & & & & & & & & \\
\hline
\end{tabular}

\#Strain represents itself

MRC-DPRU1765 represent one other strain from Zambia

MRC-DPRU1369 represent three other strains from Kenya

protection against diverse rotavirus strains, including G12 with vaccine efficacy of 51.5\% [37]. Similar results were observed with the RotaTeq vaccine study in three African countries [38]. Importantly, rotavirus vaccines have been shown to exercise protection via the immune responses to the VP4 neutralization antigens also [55], and the VP4 $\mathrm{P}[8]$ is shared between both vaccines and a proportion of the G12 strains evaluated, those with G12P[8]. Thus, understanding the genetic variability of both the VP4 and VP7 genes of the circulating G12 rotavirus strains should provide insights into the evolutionary relationships and potential biological advantages of these strains in Africa.

Phylogenetic analysis of G12 rotavirus strains globally, shows segregation of the strains into four lineages (I IV). Lineage I is the prototype strain L26 identified in 1987 and which was not apparently biologically competitive in humans and did not spread; lineage II is the G12P[9] strains from Asia which appear to be a unique class of natural reassortants with a VP4 P[9]; and lineage IV includes the only porcine strain (G12P[7]) [17, 56, 57]. Lineage III strains, on the other hand, are the mostly contemporary G12 strains detected since the early-2000's and which are now globally prevalent in most continents. This analysis confirms that the genotype G12 strains circulating in these six sub-Saharan African countries (Ethiopia, Kenya, Rwanda, Tanzania, Togo and Zambia) clustered in lineage III with strains circulating all over the world, showing the dominance and biological competitiveness of these strains, which have persisted over the last two decades in most continents [58-60]. The evolutionary rate of G12 genotype $(1.016 \times 10-3$ nucleotide substitutions/site/year $)$ observed in this study is well within the ranges that have been reported by several investigators [17, 61, 62]. The estimated time to the most recent ancestor of lineage III strains is 1992 which is similar to a previous estimate of 1995 [47] and the African strains - although scattered within the three sub-clusters - show their most recent ancestor to be from the late 1990s. This reflects the epidemiologic data, which reported the first isolation of G12 strains in the African continent in 2004. The observed diversification of our African strains in three sub-clusters is not due to their country of isolation, but more likely due 
to three different ancestral strains emerging at approximately the same time. This trend can be applied to globally circulating G12 strains belonging to lineage III [62].

Evidence of genetic variation was observed amongst the four G12 lineages in this study. Amino acid substitution S25N (VR2), N87S (antigenic region A) and A213T (antigenic region C) in lineages II \& III, segregate between the prototype lineage I detected in 1987 and the porcine lineage IV. The lineages were further characterised by the amino acid substitutions A125S in VR6 and V142I in antigenic region B detected only in the current circulating lineage III strains. This latter change from Valine to Isoleucine, where the amino acids share similar chemical properties, might not impose a conformational change to the VP7 protein. However, the A125S substitution, in which Alanine acquired a hydroxyl group to change to Serine over the period of early 2000 s to late 2000s could influence the capsid structure. The mechanism of rotaviruses mutating to advance epidemiological spread was observed with recent G2 rotavirus strains belonging to lineage IVa that spread globally. All these strains exhibited an amino acid substitution D96N which seemed to confer survival advantage to these lineage IVa G2 rotavirus strains [63]. It needs to be investigated further whether the A125S amino acid substitution observed in lineage III G12 strains has contributed to its competitiveness and spread. The amino acid substitutions and phylogenetic clustering of the study strains away from the porcine lineage IV, indicates that they are not genetically related although animalhuman rotavirus transmission is often reported in the African continent.

Amino acids changes within the antigenic regions of VP7 can result in alteration to the antigenicity of the virus and potentially enhance immunity [47]. It has been shown that the antibodies targeting neutralization epitopes stabilize the capsid and prevent uncoating of the virus which is required for viral replication [64]. Zeller and colleagues proposed that differences in the neutralizing epitopes in VP4 could undermine the vaccines effectiveness [47]. If the vaccine efficacy is mediated through the VP4 antigen, then considering these mutations may provide further insight. The study strains had similar amino acids in most of the antigenic epitopes to the VP4 P[8] gene of RotaTeq, with some differences to Rotarix, which is the preferred vaccine in most African countries. The major amino acid substitution is in position 131, in which Rotarix had a Serine and RotaTeq and study strains had an Arginine.

The G12 rotaviruses appear to have emerged irrespective of the use of rotavirus vaccines and continue circulating in countries that have not introduced the vaccines, indicating the natural circulation and competitiveness of these human viral strains. For example, rotavirus vaccines were introduced in the six countries included in this study between 2012 and 2014 and the G12 strains analysed in this study were collected between 2010 and 2014. To substantiate further, various studies from Ethiopia have reported G12 rotaviruses as a dominant strain both pre- and post-vaccine introduction [65].

It is therefore not possible to conclude that the prevalence of G12 strains was affected by vaccine introduction. Possibly, assessing the G12 strains that have emerged in Latin America and Africa at different stages after rotavirus vaccine introduction might shed light on the evolutionary pressure exerted by the vaccines.

\section{Conclusion}

The study findings suggest that the novel G12 strains circulating in African countries are highly similar at the nucleotide and amino acid level, irrespective of geographical distribution and year of detection. The African G12P[8] and G12P[6] rotavirus strains belonging to lineage III circulating in these countries are not unique and are the same as the globally circulating rotavirus G12 strains and there is no evidence of molecular evolutionary pressure from widespread vaccine use. The antigenic epitopes display limited diversity to each other and other global strains, including to the two rotavirus vaccines (RotaTeq and Rotarix), indicating that this is unlikely to be associated with sustained circulation over time in Africa. The G12 strains diversified into three sub-clusters with ancestries estimated to the late 1990s and are evolving at $1.016 \times 10^{-3}$ nucleotide substitutions/site/year sustaining this strain overtime. However, as new rotavirus vaccines which do not carry the common human rotavirus VP4 genotype $(\mathrm{P}[8])$, such as RotaVac and RotaSIIL from India [66, 67] have been pre-qualified by $\mathrm{WHO}$ and are introduced in selected African countries, it will be imperative to continue genotypic surveillance to identify and monitor emerging strains.

\section{Supplementary Information}

The online version contains supplementary material available at https://doi. org/10.1186/s12879-020-05745-6.

\section{Additional file 1.}

\footnotetext{
Abbreviations

AFRO: African Regional Office of WHO; AR: Antigenic regions; DPRU: Diarrheal Pathogens Research Unit; dsRNA: Double stranded Ribo-Nucleic Acid; ETH: Ethiopia; GSK: GlaxoSmith Kline; HIV: Human immunodeficiency virus; HPD: High posterior density; ICTV: International Committee for Taxonomy of Viruses; KEN: Kenya; MCMC: Markov Chain Monte Carlo; MTA: Materials Transfer Agreement; MREC: MEDUNSA Research and Ethics Committee; NSP: Non-structural protein; PCR: Polymerase chain reaction; RT-PCR: Reverse transcriptase polymerase chain reaction; RWA: Rwanda; TZA: Tanzania; TGO: Togo; VR: Variable regions; VP4: Viral protein 4; VP7: Viral protein 7; VP8*: Viral protein $8^{*}$ where the ${ }^{*}$ denotes a cleavage product of VP4; WHO: World Health Organization
} 


\section{Acknowledgements}

We wish to thank Dr. Mathew D Esona, CDC for his technical support for the Bayesian analysis and interpretation of the results observed. Further acknowledgement goes to WHO AFRO, African Rotavirus Surveillance Network and representatives of the Ministries of Health from Ethiopia (A Abebe and F Tassew), Kenya (JB Ochieng, B Mwinyi, N Kiulia and I Amina), Rwanda (J Uwimana), Tanzania (D Kaloya, A Mohamed, A Hokororo and C Kamugisha), Togo (T Segla-Dangloba and E Tsolenyanu, Uganda (A Mulindwa, A Odiit and A Kisakye), Zambia (JS Chibumbya and EM Mpabalwani) and Zimbabwe (C Berejena, A Shonai, A Mukaratirwa and P Nziramasanga).

\section{Authors' contributions}

KGR and MPG conducted the laboratory work of the study, supported analysis and drafting of the manuscript. LMS, MJM and JMM conceived of the study design, supported analysis and interpretation of the results and supported technical writing of the manuscript. MMN and JMM provided rotavirus strains and supported interpretation of the genomic sequences. ADS supported data analysis and drafting of the scientific manuscript. All authors read and approved the final manuscript.

\section{Funding}

The study was funded by research grants from the South African Medical Research Council, Tygerberg, the South African National Research Foundation, Pretoria, and the Poliomyelitis Research Foundation, Sandringham, Johannesburg. The study was also partially supported by a grant awarded to MMN by Bill \& Melinda Gates Foundation (BMGFOPP1180423). The funding agencies were not involved in the study design, collection of material or laboratory methods utilized, nor in the interpretation of the data. Prof Duncan Steele was involved in supervising the data analysis and drafting of the manuscript.

The views and opinions expressed in this article are those of the authors and do not necessarily reflect the position of the Bill \& Melinda Gates Foundation, the WHO or the South African Medical Research Council, or other funding agencies.

\section{Availability of data and materials}

The partial VP7 and VP4 sequences have been made available on the NCBI GenBank database (Accession numbers: MK059426 - MK059453, MT995937MT995938).

\section{Ethics approval and consent to participate}

The Research \& Ethics Committee of Sefako Makgatho Health Sciences University approved the study which was conducted in the laboratories of the university's Diarrheal Pathogen Research Unit, Department of Virology (MREC/P/237/2014).

The WHO Research Ethics Review Committee granted an 'exemption activity', noting that the procedures involved in the study sample collection are part of routine hospital-based rotavirus surveillance. The diarrheal stool samples were collected as routine diagnostic clinical specimens when the parents brought their child to a health facility for clinical management, in Ethiopia, Kenya, Rwanda, Tanzania, Togo and Zambia, and no written informed consent was obtained.

As part of the WHO-coordinated rotavirus surveillance network, the archived rotavirus-positive specimens, were anonymized and utilized for strain characterization under a Technical Service agreement and a Materials Transfer Agreement to the WHO AFRO Regional Reference Laboratory based at Sefako Makgatho Health Services University.

\section{Consent for publication}

Not applicable.

\section{Competing interests}

The authors declare they have no competing interests.

Prof AD Steele declaration:

I am employed by the Bill \& Melinda Gates Foundation which is working on rotavirus vaccine development and deployment. Understanding rotavirus strain diversity and evolution, including under possible vaccine pressure, is important. The Bill \& Melinda Gates Foundation partially funded the African Enteric Viruses Genome Initiative (AEVGI) at the University of Free State. I was not involved in sample selection or the laboratory methodology used. I was engaged in the interpretation of the data and the drafting and approval of the manuscript as the senior corresponding author.

\section{Author details}

'Diarrhoeal Pathogens Research Unit, Department of Virology, WHO AFRO Rotavirus Regional Reference Laboratory, Sefako Makgatho Health Sciences University, Pretoria, South Africa. ${ }^{2}$ Next Generation Sequencing Unit and Department of Medical Microbiology and Virology, Faculty of Health Sciences, University of the Free State, Bloemfontein, South Africa. ${ }^{3}$ National Health Laboratory Service, Department of Molecular Medicine and Haematology, Charlotte Maxeke Johannesburg Academic Hospital, Johannesburg, South Africa. ${ }^{4}$ African Rotavirus Surveillance Network, Immunization, Vaccines and Development Cluster, WHO African Regional Office, Brazzaville, Congo. ${ }^{5}$ South African Medical Research Council, Soutpansberg Road, Pretoria, South Africa. ${ }^{6}$ Present address: Enteric and Diarrheal Diseases, Global Health, Bill \& Melinda Gates Foundation, Seattle, WA, USA.

\section{Received: 21 July 2020 Accepted: 27 December 2020}

Published online: 22 January 2021

\section{References}

1. GBD 2016 Diarrhoeal Disease Collaborators. Estimates of the global, regional, and national morbidity, mortality, and aetiologies of diarrhoea in 195 countries: a systematic analysis for the Global Burden of Disease Study 2016. Lancet Infect Dis. 2018;18(11):1211-28.

2. Troeger C, Khalil IA, Rao PC, et al. Rotavirus Vaccination and the Global Burden of Rotavirus Diarrhea Among Children Younger Than 5 Years. JAMA Pediatr. 2018;172(10):958-65.

3. Clark A, Black R, Tate J, et al. Estimating global, regional and national rotavirus deaths in children < 5 years: Current approaches, new analyses and proposed improvements. PLoS One. 2017;12(9):e0183392. https://doi.org/10. 1371/journal.pone.0183392.

4. Tate JE, Burton AH, Boschi-Pinto C, Parashar UD. Global, regional and national estimates of rotavirus mortality in children $<5$ years of age, 2000 2013. Clin Infect Dis. 2016;62:S96-105.

5. Burnett $\mathrm{E}$, Jonesteller CL, Tate JE, Yen C, Parashar UD. Global Impact of Rotavirus Vaccination on Childhood Hospitalizations and Mortality from Diarrhea. J Infect Dis. 2017;215(11):1666-72.

6. Shah M, Tate JE, Mwenda JM, Steele AD, Parashar U. Estimated reductions in childhood deaths and hospitalizations after the implementation of rotavirus vaccines. Exp Rev Vaccines. 2017;16:987-98.

7. Estes MK, Greenberg HB. Rotaviruses. In: Knipe DM, Howley PM, Cohen Jl, Griffin DE, Lamb RA, Martin MA, Racaniello VR, Roizman B, editors. Fields Virology. 6th ed. Philadelphia: Wolters Kluwer/Lippincott, Williams and Wilkins; 2013. p. 1347-401.

8. Matthijnssens J, Ciarlet M, McDonald SM, et al. Uniformity of rotavirus strain nomenclature proposed by the Rotavirus Classification Working Group (RCWG). Arch Virol. 2011;156(8):1397-413.

9. Rotavirus Classification Working Group (RCWG). Newly assigned genotypes. https://rega.kuleuven.be/cev/viralmetagenomics/virus-classification/minutesof-the-7th-rcwg-meeting (Accessed May 2018).

10. Matthijnssens J, Van Ranst M. Genotype constellation and evolution of group A rotaviruses infecting humans. Curr Opin Virol. 2012;2(4):426-33.

11. Bányai K, László B, Duque J, Steele AD, Nelson EA, Gentsch JR, Parashar UD. Systematic review of regional and temporal trends in global rotavirus strain diversity in the pre rotavirus vaccine era: insights for understanding the impact of rotavirus vaccination programs. Vaccine. 2012;30(Suppl 1):A12230.

12. Dóró R, László B, Martella V, Leshem E, Gentsch J, Parashar U, Bányai K. Review of global rotavirus strain prevalence data from six years post vaccine licensure surveillance: Is there evidence of strain selection from vaccine pressure? Infect Genet Evol. 2014;28:446-61.

13. Steele AD, Peenze I, de Beer MC, et al. Anticipating rotavirus vaccines: Epidemiology and surveillance of rotavirus in South Africa. Vaccine. 2003;21: 354-60.

14. Mwenda JM, Ntoto KM, Abebe A, Enweronu-Laryea C, Amina I, Mchomvu J, Kisakye A, Mpabalwani EM, Pazvakavambwa I, Armah GE, Seheri LM, Kiulia NM, Page N, Widdowson MA, Steele AD. Burden and epidemiology of rotavirus diarrhea in selected African countries: preliminary results from the African Rotavirus Surveillance Network. J Infect Dis. 2010;202(Suppl):S5-S11. 
15. Seheri M, Nemarude L, Peenze I, Netshifhefhe L, Nyaga MM, Ngobeni HG, Maphalala G, Maake LL, Steele AD, Mwenda JM, Mphahlele JM. Update of rotavirus strains circulating in Africa from 2007 through 2011. Pediatr Infect Dis J. 2014;33(Suppl 1):S76-84.

16. Nyaga MM, Tan Y, Seheri ML, Halpin RA, Akopov A, Stucker KM, Fedorova NB, Shrivastava S, Steele AD, Mwenda JM, Pickett BE, Das SR, Jeffrey Mphahlele M. Whole-genome sequencing and analyses identify high genetic heterogeneity, diversity and endemicity of rotavirus genotype P[6] strains circulating in Africa. Infect Genet Evol. 2018;63:79-88.

17. Matthijnssens J, Heylen E, Zeller M, Rahman M, Lemey P, Van Ranst M. Phylodynamic analyses of rotavirus genotypes G9 and G12 underscore their potential for swift global spread. Mol Biol Evol. 2010;27(10):2431-6.

18. Taniguchi K, Urasawa T, Kobayashi N, Gorziglia M, Urasawa S. Nucleotide sequence of VP4 and VP7 genes of human rotaviruses with subgroup I specificity and long RNA pattern: implication for new $\mathrm{G}$ serotype specificity. J Virol. 1990;64(11):5640-4.

19. Griffin DD, Nakagomi T, Hoshino Y, Nakagomi O, Kirkwood CD, Parashar UD, Glass RI, Gentsch JR. National Rotavirus Surveillance System. Characterization of nontypeable rotavirus strains from the United States: identification of a new rotavirus reassortant $(P 2 A[6], G 12)$ and rare P3[9] strains related to bovine rotaviruses. Virology. 2002;294(2):256-69.

20. Banerjee I, Ramani S, Primrose B, Iturriza-Gomara M, Gray JJ, Brown DW, Kang G. Modification of rotavirus multiplex RT-PCR for the detection of G12 strains based on characterization of emerging G12 rotavirus strains from South India. J Med Virol. 2007;79(9):1413-21.

21. Rahman M, Matthijnssens J, Yang X, Delbeke T, Arijs I, Taniguchi K, IturrizaGómara M, Iftekharuddin N, Azim T, Van Ranst M. Evolutionary history and global spread of the emerging g12 human rotaviruses. J Virol. 2007;81(5):2382-90.

22. Page NA, de Beer MC, Seheri LM, Dewar JB, Steele AD. The detection and molecular characterization of human G12 genotypes in South Africa. J Med Virol. 2009;81(1):106-13.

23. Cunliffe NA, Ngwira BM, Dove W, Nakagomi O, Nakagomi T, Perez A, Hart CA, Kazembe PN, Mwansambo CC. Serotype G12 rotaviruses, Lilongwe, Malawi. Emerg Infect Dis. 2009;15(1):87-90.

24. Oluwatoyin Japhet M, Adeyemi Adesina O, Famurewa O, Svensson L, Nordgren J. Molecular epidemiology of rotavirus and norovirus in lle-lfe, Nigeria: high prevalence of G12P[8] rotavirus strains and detection of a rare norovirus genotype. J Med Virol. 2012;84(9):1489-96.

25. Enweronu-Laryea CC, Sagoe KW, Damanka S, Lartey B, Armah GE. Rotavirus genotypes associated with childhood severe acute diarrhoea in southern Ghana: a cross-sectional study. Virol J. 2013;14(10):287.

26. Ndze VN, Papp H, Achidi EA, Gonsu KH, László B, Farkas S, Kisfali P, Melegh B, Esona MD, Bowen MD, Bányai K, Gentsch JR, Odama AM. One-year survey of human rotavirus strains suggests the emergence of genotype G12 in Cameroon. J Med Virol. 2013;85(8):1485-90.

27. Kiulia NM, Nyaga MM, Seheri ML, Wolfaardt M, van Zyl WB, Esona MD, Irimu G, Inoti M, Gatinu BW, Njenga PK, Taylor MB, Nyachieo A. Rotavirus G and P types circulating in the eastern region of Kenya: predominance of $G 9$ and emergence of G12 genotypes. Pediatr Infect Dis J. 2014;33(Suppl 1):S85-8.

28. Moyo SJ, Blomberg B, Hanevik K, Kommedal O, Vainio K, Maselle SY, Langeland N. Genetic diversity of circulating rotavirus strains in Tanzania prior to the introduction of vaccination. PLoS One. 2014;9(5):e97562.

29. Tsolenyanu E, Seheri M, Dagnra A, Djadou E, Tigossou S, Nyaga M, Adjeoda E, Armah G, Mwenda JM, Atakouma Y. Surveillance for rotavirus gastroenteritis in children less than 5 years of age in Togo. Pediatr Infect Dis J. 2014;33(Suppl 1):S14-8.

30. Madhi SA, Cunliffe NA, Steele AD, et al. Effect of human rotavirus vaccine on severe diarrhoea in African infants. N Engl J Med. 2010;362:1617-24.

31. Armah GGE, Sow S, Breiman RF, et al. Efficacy of pentavalent rotavirus vaccine against severe rotavirus gastroenteritis in infants in developing countries in sub-Saharan Africa. Lancet. 2010;376:606-14.

32. Clark HF, Offit PA, Ellis RW, et al. The development of multivalent bovine rotavirus (strain WC3) reassortant vaccine for infants. J Infect Dis. 1996;174:S73-80.

33. Bernstein DI, Smith VE, Sherwood JR, et al. Safety and immunogenicity of a live attenuated human rotavirus vaccine 89-12. Vaccine. 1998;16:381-7.

34. Vesikari T, Matson DO, Dennehy $P$, et al. Safety and efficacy of a pentavalent human-bovine (WC3) reassortant rotavirus vaccine. N Engl J Med. 2006; 354(1):23-33.

35. Ruiz-Palacios GM, Pérez-Schael I, Velázquez FR, et al. Safety and efficacy of an attenuated vaccine against severe rotavirus gastroenteritis. N Engl J Med. 2006;354(1):11-22
36. Vesikari T, Karvonen A, Prymula R, et al. Efficacy of human rotavirus vaccine against rotavirus gastroenteritis during the first 2 years of life in European infants: randomised, double-blind controlled study. Lancet. 2007;370(9601): 1757-63.

37. Steele AD, Neuzil KM, Cunliffe NA, Madhi SA, Bos P, Ngwira B, Witte D, Todd S, Louw C, Kirsten M, Aspinall S, Van Doorn LJ, Bouckenooghe A, Suryakiran PV, Han HH. Human rotavirus vaccine Rotarix ${ }^{\mathrm{TM}}$ provides protection against diverse circulating rotavirus strains in African infants: a randomized controlled trial. BMC Infect Dis. 2012;12:213.

38. Breiman RB, Zaman K, Armah GE, et al. Analyses of health outcomes from the 5 sites participating in the Africa and Asia clinical efficacy trials of the oral pentavalent rotavirus vaccine. Vaccine. 2012;30S:A24-9.

39. Yen C, Figueroa JR, Uribe ES, Carmen-Hernández LD, Tate JE, Parashar UD, Patel MM, Richardson López-Collado V. Monovalent rotavirus vaccine provides protection against an emerging fully heterotypic G9P[4] rotavirus strain in Mexico. J Infect Dis. 2011;204(5):783-6.

40. Cowley D, Donato CM, Roczo-Farkas S, Kirkwood CD. Emergence of a novel equine-like G3P[8] intergenogroup reassortant rotavirus strains associated with gastroenteritis in Australian children. J Gen Virol. 2016;97:403-10.

41. Iturriza-Gómara M, Kang G, Gray J. Rotavirus genotyping: keeping up with an evolving population of human rotaviruses. J Clin Virol. 2004;31(4):259-65.

42. Aladin F, Nawaz S, Iturriza-Gómara M, Gray J. Identification of G8 rotavirus strains determined as $\mathrm{G} 12$ by rotavirus genotyping PCR: updating the current genotyping methods. J Clin Virol. 2010;47(4):340-4.

43. Tamura K, Stecher G, Peterson D, Filipski A, Kumar S. MEGA6: Molecular Evolutionary Genetics Analysis version 6.0. Mol Biol Evol. 2013;30(12):2725-9.

44. Edgar RC. MUSCLE: multiple sequence alignment with high accuracy and high throughput. Nucleic Acids Res. 2004;32(5):1792-7.

45. Hall T. BioEdit: a user-friendly biological sequence alignment editor and analysis program for Windows 95/98/NT. Nucleic Acids Symposium Series. 1999:41:95-8.

46. Dyall-Smith ML, Lazdins I, Tregear GW, Holmes $\mathbf{H}$. Location of major antigenic sites involved in rotavirus serotype specific neutralization. Proc Natl Acad Sci USA. 1986:83:3465-8.

47. Zeller M, Patton JT, Heylen E, De Coster S, Ciarlet M, Van Ranst M, Matthijnssens J. Genetic analyses reveal differences in the VP7 and VP4 antigenic epitopes between human rotaviruses circulating in Belgium and rotaviruses in Rotarix and RotaTeq. J Clin Microbiol. 2012;50(3):966-76.

48. Rambaut A, Lam T, Max Carvalho L, Pybus OG. Exploring the temporal structure of heterochronous sequences using TempEst (formerly Path-OGen). Virus Evol. 2016;2(1):vew007. https://doi.org/10.1093/ve/vew007.

49. Drummond AJ, Ho SY, Phillips MJ, Rambaut A. Relaxed phylogenetics and dating with confidence. PLoS Biol. 2006;4:e88.

50. Drummond AJ, Rambaut A, Shapiro B, Pybus OG. Bayesian coalescent inference of past population dynamics from molecular sequences. Mol Biol Evol. 2005;22:1185-92.

51. Dormitzer PR, Sun ZY, Wagner G, Harrison SC. The Rhesus rotavirus VP4 sialic acid binding domain has a galectin fold with a novel carbohydrate binding site. EMBO J. 2002;21(5):885-97.

52. Bucardo F, Mercado J, Reyes Y, González F, Balmaseda A, Nordgren J. Large increase of rotavirus diarrhoea in the hospital setting associated with emergence of $\mathrm{G} 12$ genotype in a highly vaccinated population in Nicaragua. Clin Microbiol Infect. 2015;21(6):603.e1-7.

53. Neves MA, Pinheiro HH, Silva RS, Linhares AC, Silva LD, Gabbay YB, Silva MC, Loureiro EC, Soares LS, Mascarenhas JD. High prevalence of G12P[8] rotavirus strains in Rio Branco, Acre, Western Amazon, in the post-rotavirus vaccine introduction period. J Med Virol. 2016;88(5):782-9.

54. Tort LF, Victoria M, Lizasoain AA, Castells M, Maya L, Gómez MM, Arreseigor E, López P, Cristina J, Leite JP, Colina R. Molecular epidemiology of group A rotavirus among children admitted to hospital in Salto, Uruguay, 2011-2012: first detection of the emerging genotype G12. J Med Virol. 2015;87(5):75463.

55. Midthun K, Kapikian AZ. Rotavirus Vaccines: An overview. Clin Microbiol Rev. 1996:9:423-34.

56. Castello AA, Argüelles MH, Rota RP, Olthoff A, Jiang B, Glass Rl, Gentsch JR, Glikmann G. Molecular epidemiology of group A rotavirus diarrhea among children in Buenos Aires, Argentina, from 1999 to 2003 and emergence of the infrequent genotype G12. J Clin Microbiol. 2006:44(6):2046-50.

57. Ghosh S, Varghese V, Samajdar S, Bhattacharya SK, Kobayashi N, Naik TN. Molecular characterization of a porcine Group A rotavirus strain with $\mathrm{G} 12$ genotype specificity. Arch Virol. 2006;151(7):1329-44. 
58. da Silva MF, Fumian TM, de Assis RM, Fialho AM, Carvalho-Costa FA, da Silva Ribeiro de Andrade J, Leite JP. VP7 and VP8* genetic characterization of group A rotavirus genotype G12P[8]: Emergence and spreading in the Eastern Brazilian coast in 2014. J Med Virol. 2017:89(1):64-70.

59. Umair M, Abbasi BH, Nisar N, Alam MM, Sharif S, Shaukat S, Rana MS, Khurshid A, Mujtaba G, Aamir UB, Zaidi SSZ. Molecular analysis of group A rotaviruses detected in hospitalized children from Rawalpindi, Pakistan during 2014. Infect Genet Evol. 2017;53:160-6.

60. João ED, Strydom A, O'Neill HG, Cuamba A, Cassocera M, Acácio S, Mandomando I, Motanyane L, Page N, de Deus N. Rotavirus A strains obtained from children with acute gastroenteritis in Mozambique, 20122013: G and P genotypes and phylogenetic analysis of VP7 and partial VP4 genes. Arch Virol. 2018;163(1):153-65.

61. Nakagomi T, Do LP, Agbemabiese CA, Kaneko M, Gauchan P, Doan YH, Jere KC, Steele AD, Iturriza-Gomara M, Nakagomi O, Cunliffe NA. Whole-genome characterisation of $\mathrm{G} 12 \mathrm{P}[6]$ rotavirus strains possessing two distinct genotype constellations co-circulating in Blantyre, Malawi, 2008. Arch Virol. 2017;162(1):213-26.

62. Saikruang W, Khamrin P, Malasao R, Kumthip K, Ushijima H, Maneekarn N. Complete genome analysis of a rare G12P[6] rotavirus isolated in Thailand in 2012 reveals a prototype strain of DS-1-like constellation. Virus Res. 2016; 224:38-45.

63. Doan YH, Nakagomi T, Cunliffe NA, Pandey BD, Sherchand JB, Nakagomi O. The occurrence of amino acid substitutions D96N and S242N in VP7 of emergent G2P[4] rotaviruses in Nepal in 2004-2005: A global and evolutionary perspective. Arch Virol. 2011:156(11):1969-78.

64. Trask SD, McDonald SM, Patton JT. Structural insights into the coupling of virion assembly and rotavirus replication. Nat Rev Microbiol. 2012;10(3):16577.

65. Damtie D, Melku M, Tessema B, Vlasova AN. Prevalence and genetic diversity of rotaviruses among under-five children in Ethiopia: a systematic review and meta-analysis. Viruses. 2020;12(1):E62. https://doi.org/10.3390/ v12010062.

66. Bhandari N, Rongsen-Chandola T, Bavedekar A, et al. Efficacy of a monovalent human-bovine (116E) rotavirus vaccine in Indian infants: A randomized double-blind, placebo-controlled trial. Lancet. 2014;383(9935): 2136-43.

67. Kulkarni PS, Desai S, Tewari T, et al. A randomized Phase III clinical trial to assess the efficacy of a bovine-human reassortant pentavalent rotavirus vaccine in India infants. Vaccine. 2017;35:6228-37.

\section{Publisher's Note}

Springer Nature remains neutral with regard to jurisdictional claims in published maps and institutional affiliations.

Ready to submit your research? Choose BMC and benefit from:

- fast, convenient online submission

- thorough peer review by experienced researchers in your field

- rapid publication on acceptance

- support for research data, including large and complex data types

- gold Open Access which fosters wider collaboration and increased citations

- maximum visibility for your research: over $100 \mathrm{M}$ website views per year

At $\mathrm{BMC}$, research is always in progress.

Learn more biomedcentral.com/submissions 